\title{
El nacionalismo vasco en el exilio en los Estados Unidos: masculinidad vasca e identidad transnacional en White Stars of Freedom (1942), de Mirim Isasi y Melcena Burns Denny
}

\author{
Basque Nationalism in Exile in the United States: Basque \\ Masculinity and Transnational Identity in White Stars of \\ Freedom (1942), by Mirim Isasi and Melcena Burns Denny
}

\author{
IKER GONZÁLEZ-ALLENDE \\ University of Nebraska-Lincoln \\ igonzalezallende2@unl.edu
}

Recibido: octubre de 2019. Aceptado: enero de 2020

\begin{abstract}
Resumen: Este artículo analiza el componente didáctico y propagandístico de White Stars of Freedom, de Mirim Isasi y Melcena Burns Denny. Mi argumento es que esta novela reproduce la ideología oficial del nacionalismo vasco en el exilio tras la Guerra Civil Española al idealizar a los Estados Unidos como tierra de promisión y al enfatizar la existencia de valores similares en los Estados Unidos y Euskadi, como la libertad, la democracia y el cristianismo. La obra busca promover el apoyo de Estados Unidos al nacionalismo vasco en el exilio. Asimismo, a través de la maduración de Narbik, un muchacho vasco que trabaja como pastor en Euskadi, se resaltan valores tradicionales de la masculinidad en los que la cultura vasca coincidía con la estadounidense: la fuerza física y mental para la superación de obstáculos, la lealtad, la laboriosidad, la independencia y el deseo de ganar. El exilio positivo de Narbik en los Estados Unidos refuerza su masculinidad al proveerle de oportunidades personales y profesionales. Narbik representa una identidad transnacional en la que, después de nacionalizarse estadounidense, destina su fidelidad política solo a los Estados Unidos mientras mantiene al mismo tiempo su cultura y raíces vascas.
\end{abstract}

Palabras clave: Exilio vasco, masculinidad vasca, nacionalismo vasco, Estados Unidos, Mirim Isasi 


\begin{abstract}
This article analyzes the didactic and propagandistic component of White Stars of Freedom, by Mirim Isasi and Melcena Burns Denny. I contend that this novel reproduces the official ideology of the Basque nationalism in exile after the Spanish Civil War by idealizing the United States as a promised land and stressing the existence of similar values in the United States and Euskadi, such as liberty, democracy and Christianity. The work aims to promote the support of the United States to the Basque nationalism in exile. Additionally, through the growth of Narbik, a Basque boy who works as a shepherd in Euskadi, the authors emphasize traditional values of masculinity in which Basque culture converges with the American one: physical and mental strength to overcome obstacles, loyalty, industriousness, independence, and the will to win. Narbik's positive exile in the United States reinforces his masculinity by providing him with personal and professional opportunities. Narbik represents a transnational identity in which, after his naturalization as a United States citizen, he exclusively devotes his political loyalty to the United States while maintaining his Basque culture and roots.
\end{abstract}

Keywords: Basque exile, Basque masculinity, Basque nationalism, United States of America, Mirim Isasi

\title{
I.- ISASI Y EL EXILIO NACIONALISTA VASCO
}

La Guerra Civil Española y la posterior implantación de la dictadura franquista produjo el exilio de los principales intelectuales vascos, quienes buscaron refugio mayoritariamente en países de América como México, Argentina y Venezuela. La elección de esos países se debió al hecho de compartir el idioma y existir en esas tierras una larga tradición de emigración vasca. Gloria Totoricagüena señala que alrededor de cincuenta mil vascos se exiliaron en Latinoamérica y que las comunidades de emigrantes vascos que vivían allí les ayudaron a establecerse (2005: 278). La producción cultural del exilio vasco no alcanzó el esplendor de otros exilios, pero, a pesar de ello, en palabras de José Ángel Ascunce Arrieta, «poseyó un entramado medio muy rico y vigoroso» (1999: 8). Emilio Palacios Fernández también asevera que las obras del exilio vasco no siempre poseen una gran calidad, pero resultan relevantes por su valor testimonial y la expresión de su identidad nacional (2000: 16).

Dentro del exilio vasco se pueden distinguir dos culturas diferenciadas: la republicana vasca y la nacionalista vasca (González-Allende 2016a: 17). Mientras que la primera estaba conformada por profesionales de la cultura que se identificaban con la República española y continuaron en el exilio las labores culturales que habían realizado antes de la guerra, la segunda estaba constituida por personas mayormente relacionadas con la esfera política $\mathrm{y}$, de acuerdo a Ascunce Arrieta, detentaba un carácter testimonial y utópico que buscaba afirmar y estimular la conciencia nacional e histórica de Euskadi (2000: 79). La cultura nacionalista vasca en el exilio se materializó a través de los Centros Vascos o Euskal Etxeak, así como por la publicación de periódicos, revistas y libros. La editorial Ekin de Buenos Aires, fundada en 1942 por Isaac López Mendizabal 
y Andrés de Irujo, dio a la luz más de cien títulos sobre el País Vasco. El deseo de diseminar la historia y la cultura vascas provocó que los exiliados vascos escribieran asiduamente y que numerosos miembros del Gobierno Vasco llegaran a publicar entre tres y cinco libros (Irujo 2012: 126-27).

Las Delegaciones de Euskadi en el exilio en diversos países de América asimismo promovieron la identidad vasca, buscando influenciar a los gobiernos de las principales potencias internacionales y al mismo tiempo fomentar la unidad y solidaridad de los vascos (Sanz Goikoetxea y Álvarez Gila 2010: 15859). ${ }^{1}$ La Delegación de Nueva York tuvo especial relevancia por la presencia en ella del lehendakari José Antonio Aguirre desde 1941 hasta 1945. ${ }^{2}$ A través de esta entidad, delegados como Manuel de la Sota y Antón de Irala trabajaban para obtener apoyos en los medios católicos y en la opinión pública estadounidense, recaudar fondos de ciudadanos americanos y atraer a los emigrantes vascos hacia el nacionalismo vasco. Para ello, crearon la editorial The Basque Archives y la revista de corte político Basques: Bulletin of the Basque Delegation in the USA, de la que se publicaron seis números entre 1943 y $1944 .^{3}$

Además, en Nueva York se redactaron dos de las principales obras de la cultura nacionalista vasca en los Estados Unidos: Yanqui hirsutus, de Manuel de la Sota — escrita en 1946 pero publicada en 1949 en Buenos Aires-y De Guernica a Nueva York, pasando por Berlín, de José Antonio Aguirre - escrita en 1942, publicada en 1943 en la editorial Ekin de Buenos Aires y traducida al inglés como Escape via Berlin (1944). A pesar de que la primera obra es una novela y la segunda son unas memorias, ambas presentan numerosas similitudes por su componente ensayístico y su misma ideología, basada en la idealización de los Estados Unidos y en su caracterización como país defensor de la democracia en el mundo. ${ }^{4}$ Emilio López señala al respecto que la actitud general del Partido Nacionalista Vasco (PNV) era indudablemente favorable a los estadounidenses y que su identificación con ellos «era prácticamente total» (58).

1 En 1941 el lehendakari Aguirre subrayaba en su diario la necesidad de la cohesión de los vascos frente a las divisiones entre los españoles: «Aconsejo calma, mucha calma, fuerte unión vasca [...]. Los españoles siguen tan divididos. Nosotros, como he aconsejado, marchando firmes hacia adelante» (1998: 198). A pesar de ello, Eneko Sanz Goikoetxea y Oscar Álvarez Gila indican que los vascos de América no siempre se hallaban unidos, ya que había emigrantes que habían sido influidos por la propaganda franquista (2010: 160).

2 Como apunta David Mota Zurdo, desde la Delegación de Nueva York se decidían gran parte de las actividades del Gobierno Vasco en el exterior y se controlaban las labores de las Delegaciones vascas en América (2012: 16).

3 La revista estaba redactada íntegramente en inglés, con el objetivo de informar al público estadounidense sobre la dictadura de Franco y la historia de Euskadi desde el punto de vista del Gobierno Vasco (Totoricagüena 2003: 206).

4 La semejanza entre ambas obras no es casual, ya que Sota ayudó a Aguirre en la elaboración de De Guernica a Nueva York y actuó como uno de sus colaboradores más íntimos durante sus años en Nueva York (González-Allende 2016b: 17). En el diario de Aguirre se aprecia la asistencia de Sota: «Manu Sota y yo, después de misa y desayuno, hemos pasado todo el día en casa preparando el índice del libro [...]. Hemos hecho seis posibles capítulos» (1998: 236). 
En este contexto del nacionalismo vasco en el exilio se sitúa la producción literaria de Mirim Isasi, una exiliada vasca que publicó dos obras en inglés en los Estados Unidos: Basque Girl (1940) y White Stars of Freedom: A Basque Shepherd Boy Becomes an American (1942), esta última en colaboración con una escritora estadounidense, Melcena Burns Denny, y con ilustraciones de Kurt Wiese. Basque Girl es una novela autobiográfica en la que la autora relata su vida bajo el nombre de Erena: su adolescencia en el ámbito rural vasco, su partida a Inglaterra para estudiar en un colegio, su compromiso con un pelotari vasco que termina muriendo al luchar por Euskadi y finalmente su decisión de exiliarse durante la Guerra Civil Española para poder ser libre, ganándose la vida con sus danzas. ${ }^{5}$

White Stars of Freedom también enfatiza la importancia de la libertad personal y nacional a través de la historia de Narbik Aguirre. ${ }^{6}$ Se trata de una novela de crecimiento o Bildungsroman que se enmarca dentro de la literatura juvenil y narra en primera persona la vida de un muchacho vasco que cuida las ovejas de su familia en el monte y que, por medio de su amistad con Basco George, un emigrante vasco que vive en Idaho, parte al exilio a los Estados Unidos durante la Guerra Civil. Allí trabaja como pastor hasta encontrar un puesto en el zoo de San Diego y finalmente, con veintiún años, decide convertirse en ciudadano estadounidense y alistarse en el ejército de su nuevo país para luchar en la Segunda Guerra Mundial tras el ataque a Pearl Harbor. ${ }^{7}$

En este artículo me enfocaré en White Stars of Freedom y analizaré su componente didáctico y propagandístico. Mi argumento principal es que esta novela reproduce la ideología oficial del nacionalismo vasco en el exilio al idealizar a los Estados Unidos como tierra de promisión y al enfatizar la existencia de valores similares en los Estados Unidos y Euskadi, como la libertad, la democracia y el cristianismo. Al desarrollarse mayormente en el ámbito rural vasco, la obra da a conocer el País Vasco en los Estados Unidos para promover el apoyo de este país a la causa del nacionalismo vasco durante la dictadura franquista. Asimismo, a través de la maduración del protagonista, para quien su trabajo como pastor en las montañas se convierte en un rito de paso a la mascu-

5 En el momento de la escritura de la novela, la narradora se halla en los Estados Unidos: «And I, who am writing this in a place called Hollywood, on the other side of the world from the great gray stone home of the Isasis [...]» (1940: 14). Sobre esta obra, Mari Jose Olaziregi señala que reproduce los valores del nacionalismo de Sabino Arana al presentar el País Vasco como católico, vasco-parlante y con un pasado noble (2010: 114).

6 El nombre del protagonista resulta sorprendente, ya que, a diferencia de la mayoría de los personajes de la novela, no es vasco. Se podría pensar que alude a la ciudad noruega de Narvik, donde en 1940, unos meses antes de que las autoras comenzaran a escribir la obra, los aliados vencieron a los alemanes en una batalla durante la Segunda Guerra Mundial. El nombre quizás también se deba a la conexión vasco-noruega a partir de las numerosas visitas a Bilbao de barcos noruegos que transportaban bacalao.

7 El primer y el último capítulo narran el día de la ceremonia de ciudadanía estadounidense de Narbik el 12 de diciembre de 1941. El ataque a Pearl Harbor por parte de los japoneses, sucedido el 7 de diciembre de ese año, se menciona en la novela como un acontecimiento que requiere el sacrificio de todos los ciudadanos del país. 
linidad desde los trece hasta los dieciséis años, la novela resalta valores tradicionales de la masculinidad en los que la cultura vasca coincidía con la estadounidense, como la fuerza física y mental para la superación de obstáculos, la lealtad, la laboriosidad, la independencia y el deseo de ganar.

El exilio de Narbik en los Estados Unidos adquiere un carácter positivo y refuerza su masculinidad al ofrecerle seguridad y libertad y proveerle de oportunidades para estudiar y mejorar profesionalmente. Su obtención de la ciudadanía americana simboliza su entrada definitiva a la masculinidad y a su vida como adulto. Narbik representa una identidad transnacional en la que su fidelidad política se destina exclusivamente para los Estados Unidos, pero manteniendo su cultura y raíces vascas. Su alistamiento en el ejército estadounidense para luchar en la Segunda Guerra Mundial y su futuro matrimonio con una chica vasca exiliada en Idaho ejemplifican esta unión identitaria de la nación de adopción con la nación de origen.

Los valores de la masculinidad tradicional de Narbik le erigen en un posible modelo para los jóvenes estadounidenses cuyo país se hallaba en guerra. Como señala Gary Schmidt, a comienzos de la década de 1940, las obras de literatura infantil y juvenil en los Estados Unidos impelían a los niños a colaborar en los esfuerzos bélicos, enfatizando el concepto de Estados Unidos como un crisol de culturas (melting pot) por el que todos los ciudadanos estadounidenses, sin importar su origen, debían unirse para luchar juntos: "America is not a place, it is people; all kinds of people from all countries» (2013: 126). El juez que instruye la ceremonia de ciudadanía de Narbik transmite precisamente ese mensaje: «But you, in your homes, and wherever you work, must never forget that the nation needs you too. [...] We need solidarity and union. Every one of us must make sacrifices» (305). ${ }^{8}$ Además, Schmidt señala que libros como el de Isasi, protagonizados por niños que huyen de conflictos bélicos en otros países, pudieron servir para concienciar a la infancia estadounidense de la relevancia de su colaboración en la guerra (2013: 132). Por este motivo White Stars of Freedom tuvo una gran acogida en Estados Unidos durante esos años y llegó a ser recomendada por Eleanor Roosevelt (Aguirre + San Sebastián 2018: 234).

El componente propagandístico de la novela provoca que Richard Etulain la considere como una mala obra: «There is too much preaching in the novel. [...] The Basque materials are engulfed by too much praise of America and its democratic ways» (1977: 10). La obvia ideología presente en sus páginas y el hecho de que es una obra mayormente creada en respuesta a las circunstancias políticas del momento han motivado su olvido y el desinterés por parte de la crítica. De hecho, no existe ninguna publicación académica sobre esta novela, sino solo referencias y menciones sueltas en estudios de conjunto. Esto también se puede deber al desconocimiento sobre la primera de las autoras, quien se sirvió del pseudónimo «Mirim Isasi» para firmar sus dos obras publicadas. $\mathrm{Su}$ verdadero nombre era Rosita Durán y había nacido en Bilbao y estudiado en

8 En la sección de agradecimientos al final de la obra, las autoras también reiteran el importante papel que realizan en la sociedad los extranjeros que se naturalizan estadounidenses: «the great contributions that naturalized citizens can make to America» (308). 
Inglaterra, lo que explicaría su dominio del inglés. En 1937 se exilió en México y posteriormente se trasladó a los Estados Unidos, donde actuaba como bailarina y pronunciaba conferencias sobre el pueblo vasco. ${ }^{9}$ Como el protagonista de su novela, Durán se hizo ciudadana americana antes de 1942 y, según Anna Aguirre y Koldo San Sebastián, se alistó como conductora de ambulancias en San Diego, no habiendo más información sobre ella a partir de entonces (2018: 235). ${ }^{10}$

Sobre la segunda autora, Melcena Burns Denny (1876-1974), sí existen más datos. Nacida en California, cultivó la poesía, narrativa y teatro, publicando en revistas como Youth's Companion y Woman's Home Companion. Antes de su matrimonio con Robert Roy Denny, publicaba bajo el nombre de L. M. Burns. Además de esta novela con Isasi, escribió The Book of Baby Mine (1915), que incluye versos e ilustraciones sobre bebés y va destinado a las madres primerizas.

Otra razón que puede explicar la ausencia de estudios críticos sobre White Stars of Freedom es su dificultad para situarla dentro de una tradición literaria nacional. Richard Etulain, David Río Raigadas y Victoria Bañales Atxirika incluyen las obras de Isasi dentro de la producción vasco-americana al estar escritas en inglés. Río Raigadas menciona los libros de Isasi como ejemplos significativos iniciales de esta literatura en la primera mitad del siglo XX porque la primera generación de emigrantes vascos en Estados Unidos, mayormente dedicada al pastoreo y con un dominio limitado del inglés, no tenía como meta prioritaria escribir literatura, sino ahorrar dinero (2002: 676). William Douglass y Jon Bilbao exponen que este desinterés de los emigrantes vascos por la escritura se debía a su formación cultural limitada y su poca valoración de la educación formal (2005: 367). A pesar de la publicación de las obras de Isasi en los años 40, Río Raigadas afirma que hasta la aparición en 1957 de Sweet Promised Land, de Robert Laxalt, hijo de emigrantes vascos, no se puede hablar del fin de la invisibilidad literaria de los vascos en los Estados Unidos (2002: 676). ${ }^{11}$

Ahora bien, considero que a pesar de naturalizarse americana y publicar en inglés, la producción literaria de Isasi se debe estudiar dentro del exilio vasco y no sólo como parte de la cultura vasco-americana. Al haber nacido en el País Vasco y llevar viviendo pocos años en Estados Unidos, su experiencia seguramente no era idéntica a la de los emigrantes de segunda generación o los vascoamericanos nacidos en Estados Unidos como Laxalt. En su caso, habría que

9 Al final de Basque Girl, Isasi manifiesta cómo representa al País Vasco a través de sus danzas: «But best of all I like to express as I dance the beauty and meaning of the Guernikaco Arbola, the national anthem of the Basque people» (249).

10 En la sección de agradecimientos de White Stars of Freedom se confirma la ciudadanía americana de Isasi: «Both of us [the authors] are United States citizens, though one of us was born Basque» (307).

11 En esta obra Laxalt ofrece una imagen positiva e idealizada del pastor vasco emigrante, basada en la vida de su padre. El éxito que alcanzó la novela se puede conectar con el incremento de la conciencia étnica en los Estados Unidos a partir de esa época (Río Raigadas 1999: 46). 
hablar de un exilio, ya que abandonó Euskadi debido a la Guerra Civil, lo que podría explicar el fuerte componente nacionalista vasco en sus obras. El hecho de que estuvieran escritas originalmente en inglés, algo atípico en las obras de ficción de los exiliados vascos, ha provocado que en gran parte hayan sido ignoradas en los estudios sobre el exilio vasco.

El contacto que Isasi mantuvo con Manuel de la Sota y la Delegación de Euskadi en Nueva York demuestra su similitud ideológica. En una carta escrita el 10 de octubre de 1940 a Jon Bilbao, Sota menciona a Isasi y su patriotismo vasco:

En North Hollywood, Calif. (Box 72) vive una señorita llamada Rosita Durán pero que usa el nombre de Mirim Isasi cuando baila y escribe. Es una mujer joven y bastante atrayente que ha descubierto con entusiasmo la patria de sus antepasados y ahora se proclama únicamente vasca. Da conferencias bailadas sobre Euzkadi. Acaba de publicar un libro titulado «Basque Girl» en GriffinPatterson Pub. de Glendale, California. Aunque contiene muchos errores, no puede ser mejor intencionado, y hay cosas que están bastante bien. En la pasta aparece nuestra bandera en colores. Si tienes dos dólares disponibles no dejes de adquirirlo. También podrías escribir[le] a ella. ¿Para qué [sic] no le arreglas una conferencia en esa Universidad? (San Sebastián 1991: 462).

Las buenas intenciones de Sota para con Isasi se repiten años más tarde, como manifiestan las autoras en la sección de agradecimientos al final de White Stars of Freedom: «Mr. Manuel de la Sota, busy in New York with the duties of the Basque Delegation, was never too busy to answer letters. It was he who gave us Aita-Aita's ancient and beautiful Basque prayer» (307). ${ }^{12}$

\section{II.- EL PAÍS VASCO Y LOS ESTADOS UNIDOS COMO NACIONES HERMANAS}

White Stars of Freedom reproduce la posición oficial laudatoria del nacionalismo vasco respecto a los Estados Unidos. De esta manera, la novela busca realizar la misma labor que pretendía el Gobierno Vasco en Nueva York: educar a los estadounidenses sobre la cultura e historia vascas y propagar su importancia y las similitudes entre Euskadi y los Estados Unidos. Totoricagüena señala que la Delegación de Euskadi en Nueva York intentaba distanciarse del Gobierno republicano español para que la identidad vasca se afianzara entre los políticos y las figuras destacadas del país (2003: 203). Para recabar su apoyo, el Gobierno Vasco se posicionó de manera incondicional en el bando de los aliados durante la Segunda Guerra Mundial, participando en redes de espionaje e información a favor de los Estados Unidos (Mota Zurdo 2017: 297). Los nacio-

12 El abuelo de Narbik suele pronunciar la siguiente oración antes de la comida: «The Pastor of the world seats us at His holy table» (121). Como indican Aguirre y San Sebastián, Sota era considerado como un asesor sobre la cultura vasca en los Estados Unidos y, por ejemplo, ayudó a Nea Colton en la elaboración de su novela The Rivers are Frozen (1942) (2018: 234-35). 
nalistas vascos tenían la esperanza de que Estados Unidos les ayudaría a expulsar a Franco de España y reconocería los derechos del pueblo vasco (López 1977: 59). ${ }^{13}$

Isasi y Denny manifiestan ficcionalmente el respaldo del nacionalismo vasco a los Estados Unidos en la Segunda Guerra Mundial cuando Narbik decide que se alistará en el ejército estadounidense sin miedo a arriesgar su vida: «As soon as I became a citizen I would enlist with the marines. The meaning of their motto, Semper Fidelis, seemed already familiar. Always Faithful! With such a motto I would follow orders and strive to do my duty wherever my new flag took me» (301). Este sacrificio por su nueva nación serviría para que el lector estadounidense se forjara una buena opinión sobre los vascos.

El trabajo de Narbik como pastor a su llegada al país era común en los emigrantes vascos. En la fecha de publicación de la novela se solía identificar positivamente al vasco en Estados Unidos con el oficio de pastor (Álvarez Gila 2016: 499). ${ }^{14}$ Sin embargo, en décadas anteriores, hasta los años 20, la concepción sobre los vascos era mayormente negativa porque vivían como nómadas, llevando las ovejas de unas tierras a otras, lo que provocó acusaciones de que se aprovechaban de los recursos naturales del país sin invertir luego en él (Totoricagüena 2005: 216). También se les reprochaba su falta de adaptación, el no aprender inglés ni convertirse en ciudadanos americanos (Douglass + Bilbao 2005: 304). Por medio de los personajes de Narbik y Basco George y su adopción de la ciudadanía americana, Isasi y Denny contrarrestarían las opiniones negativas que existían en el pasado sobre los vascos y fomentarían su aceptación y prestigio. Significativamente, el subtítulo de la novela, «A Basque Shepherd Boy Becomes an American», se refiere a la naturalización de Narbik como estadounidense.

La obra también podría estar destinada a los emigrantes de origen vasco para educarles sobre su tierra de procedencia y atraerles a la causa del nacionalismo vasco. Éste fue precisamente uno de los objetivos del Gobierno Vasco en los Estados Unidos: conseguir la adhesión de la colectividad vasca por medio de actos sociales y culturales (Sanz Goikoetxea + Álvarez Gila 2010: 185). Es posible que al situar el presente narrativo de la novela en el Oeste de Estados Unidos, donde Basco George tiene un rancho y viven ahora Narbik, su prima Begoña y su hermana pequeña Mirentxu, las autoras pretendieran influenciar políticamente a la comunidad vasca de esa zona, conocida por su desinterés hacia el nacionalismo vasco (Douglass + Bilbao 2005: 360). El Gobierno Vasco

13 Sin embargo, a partir de 1947, el Gobierno de los Estados Unidos se fue acercando progresivamente a la España franquista con el objetivo de frenar la expansión del comunismo (Mota Zurdo 2017: 298). Esto provocó, en palabras de López, que en esa época Aguirre se considerara «utilizado y luego semiabandonado por los americanos» (1977: 73).

14 Iker Saitua señala que la visión positiva de los pastores vascos emigrantes a partir de la década de 1920 se debía a que se les consideraba pertenecientes a la raza blanca y semejantes a la población anglo-europea (2018: 93). En cambio, Oscar Álvarez Gila apunta que hasta la década de 1970, en el cine y la televisión estadounidenses se incluía a los vascos dentro de los latinos e incluso se les relacionaba con los gitanos (2015: 175). 
intentó ganarse el apoyo de esos vascos — cuarenta mil, mayormente en California y Idaho, según las cifras de San Sebastián (2014: 108) — abriendo en marzo de 1940 una subdelegación en Boise, Idaho, dirigida por Jon Bilbao. Sin embargo, a pesar de los numerosos esfuerzos de Bilbao, la subdelegación no tuvo éxito y debió cerrar al de unos meses por la indiferencia de los vascos emigrantes y los obstáculos de una asociación franquista, la Independent Order of Spanish Basque Speaking People of Idaho (San Sebastián 2014: 112). ${ }^{15}$

Para combatir la propaganda franquista y lograr el apoyo de los Estados Unidos para la recuperación del autogobierno vasco, White Stars of Freedom enfatiza valores que el nacionalismo vasco considera positivos y propios de Euskadi y que coinciden con los del patriotismo estadounidense: la libertad, la democracia y el cristianismo. Se busca así informar y educar a los estadounidenses sobre las estrechas similitudes entre ambas naciones. Para transmitir las que el nacionalismo vasco valoraba como auténticas tradiciones vascas, la acción de la novela — con la excepción del primer capítulo y los dos últimos-, se desarrolla en el País Vasco rural, mayormente en el caserío de la familia de Narbik, el pueblo donde éste se halla y las montañas vascas en las que pastorea el protagonista. Como numerosas otras ideologías nacionalistas, el nacionalismo vasco de Sabino Arana idealizaba el mundo rural porque creía que en él moraba inalterable la raza vasca (Granja 2000: 31).

Isasi y Denny presentan la libertad como un valor intrínseco de la nación vasca. Esto se aprecia ya en la dedicatoria del libro: «This book is dedicated to The Democratic Ideal of Liberty». Basque Girl incluye una dedicatoria muy similar, haciendo referencia a la opresión que sufría el País Vasco bajo el franquismo: "To the unconquerable Basque love of freedom, which, crushed and broken, will yet rise again, this volume is prayerfully dedicated». La libertad vasca se relaciona con su pasado como pueblo independiente y su presente de lucha para alcanzar el autogobierno y la independencia de España y Francia. Así lo indica Narbik:

It puzzled me that a race like ours, invincible in spirit, had lost national and social freedom. For a century Basques had striven for self-government. Ours was an ancient, pure-blooded race, with a language unrelated to any other spoken on earth. But it was being stamped out, along with many old customs. Yet our struggle for national independence went on. Our great patriot, Arana-Goiri, had called the attention of the world to our demands for freedom when Cuba was freed. He was thrown into prison for his efforts (62).

Al crear la imagen de un pasado ancestral y singular del pueblo vasco que se halla en peligro de perderse, el narrador protagonista justifica los deseos de libertad política de Euskadi. La mención al padre del nacionalismo vasco y al

15 En una carta a Sota fechada el 14 de junio de 1940, Bilbao se lamentaba de las dificultades a las que se había tenido que enfrentar en Boise: «Se ha fracasado, bien por mi falta o por lo que sea. [...] no he tenido ayuda alguna, muy al contrario; individuos que yo creía me ayudaban han sido los que más trabas me han puesto» (San Sebastián 1991: 455). 
telegrama que envió en 1902 a Theodore Roosevelt, presidente de Estados Unidos, felicitándole por la independencia de Cuba y expresando los deseos de libertad del País Vasco, refleja cómo el nacionalismo vasco históricamente ha confiado en los Estados Unidos para la consecución de su autonomía.

La libertad política de Euskadi implica en la novela el rechazo a los extranjeros o a las razas foráneas que buscan aprovecharse de la nación vasca. Las autoras critican duramente al matrimonio de turistas ingleses que visitan la montaña en la que se encuentra Narbik. La turista se encapricha del perro pastor de Narbik, insistiendo en comprárselo por cada vez más dinero y, a pesar de la constante negativa de Narbik, el perro desaparece con ellos tras ser engañado con azúcar. El turismo se muestra aquí como una irrupción y amenaza a las costumbres y riqueza natural de Euskadi. De manera similar se representa a los gitanos con los que interactúa Narbik en la montaña. A la mujer gitana se la describe como sucia y embustera, dedicada a entretener a Narbik mientras sus dos hijos cortan y roban la lana de las ovejas. La imagen de los gitanos como ladrones revela cómo el nacionalismo vasco rechazaba lo considerado foráneo porque creía que corrompía a la nación vasca física y moralmente. Desde su perspectiva, la libertad de la nación requería defenderse de este tipo de intrusiones.

Narbik aprende sobre la nación vasca a través de Begoña, su prima de diciesiete años que vive en el caserío familiar tras haber sido adoptada por los padres de Narbik. ${ }^{16}$ Es ella quien le teje una ikurriña para que la ponga en su tienda de pastor y le recuerda que Euskadi es un pueblo libre: «This flag is our emblem of freedom. Our Basque provinces may belong to France and Spain, but inside [...] we are free» (54). Begoña representa en la novela el prototipo de la madre de la nación vasca que, como explica Nerea Aresti, se desarrolla en las décadas de 1920 y 1930 con la labor de educar a las futuras generaciones en el ideal patriótico y cristiano (2014: 298). ${ }^{17}$ Sin embargo, Begoña también simboliza el modelo de mujer vasca fuerte cuando rompe con costumbres patriarcales y decide rechazar su matrimonio concertado desde niña, no llevar un pañuelo en la cabeza y trabajar como mecanógrafa e intérprete en un hotel de Bilbao. Aresti explica cómo Sabino Arana consideraba positivo este tipo de mujer vasca fuerte en situaciones excepcionales, sin que ello implicara hacer extensible esta valoración a todas las mujeres (2014: 289). En el caso de Begoña, su patriotismo vasco y fortaleza le permiten romper los moldes tradicionales de género y no sufrir el estigma social. ${ }^{18}$

16 El nombre de Begoña se transcribe como «Begona» a lo largo de toda la novela debido a la inexistencia de la «ñn en el alfabeto inglés y las dificultades que acarrearía su pronunciación en el lector estadounidense.

17 La madre de Narbik desempeña un papel secundario y pasivo en la novela. Siempre se presenta supeditada a su marido y conectada con la bondad y el cariño incondicional hacia los suyos: «She was a quiet, expert homemaker, always busy» (44). Por lo tanto, sigue el modelo ideal de mujer rural o etxekoandrea, el cual, según Margaret Bullen, consiste en ser una buena madre, trabajadora y esposa eficiente (2003: 61).

18 La única persona que la critica públicamente por alejarse del papel tradicional de la mujer vasca es Valintin, pero esto se debe a que Begoña se niega a casarse con él. El padre de Narbik 
Además, Begoña ejemplifica la importancia de la libertad individual en la cultura vasca. Ella misma relaciona la libertad de la nación con la del individuo en un discurso que da en Gernika: «No nation can endure without freedom. The little Basque race, that considers itself a nation, has striven for freedom through the centuries. National autonomy is what we seek. Personal freedom, national freedom — both are dear to us» (260). El nacionalismo vasco ensalzaba la libertad personal como uno de sus valores principales. En En torno al carácter vasco, Sota lo expresa así: «Para el vasco, el ser libre no es un derecho o un privilegio; es un deber. Su primera obligación es la de ser hombre, y nadie puede ser hombre sin ser libre al mismo tiempo. Libertad y sentido humano son una misma cosa» (1991: 20).

Isasi y Denny consideran que este valor del nacionalismo vasco es asimismo una cualidad primordial en la cultura estadounidense. En la sección de los agradecimientos lo explicitan claramente: «Basques, like Americans, have always loved freedom» (307). Basco George también subraya esta similitud entre las dos naciones cuando dice: «Here freedom is loved as it is in the United States» (91). Basco George cita la Declaración de Independencia de los Estados Unidos para enfatizar la necesidad de la libertad individual: «Life, liberty, and the pursuit of happiness - every human being is entitled to these rights» (197). De esta manera, se posiciona a favor de Begoña cuando Valintin, el hombre al que la prometieron en matrimonio siendo una niña y que ella rechaza, le acusa de romper con las costumbres vascas: «You have a right to personal liberty, Begona, even when it conflicts with traditional customs» (188). Por lo tanto, la libertad en la mujer implica su derecho a tomar sus propias decisiones. El modelo de mujer vasca fuerte que encarna Begoña se presenta de manera similar al de la mujer moderna de los Estados Unidos.

Ahora bien, el símbolo más claro de libertad que permea en la novela es el de las estrellas en la bandera de los Estados Unidos, el cual aparece ya en el título. Citando a George Washington, Basco George le revela a Narbik que las estrellas de la bandera simbolizan el cielo, mientras que las rayas blancas representan la libertad (245-46). Al reflexionar sobre las estrellas, Narbik las relaciona con la estrella de Belén, la cual, bajo su punto de vista, guió a la humanidad hacia la libertad, y concluye que, para él, en la bandera de los Estados Unidos las estrellas no representan los estados, sino la libertad: " "They are not states for me", I said, still deep in thought. "They are the white stars of freedom"» (246). A través de esta metáfora, no sólo se enfatiza la importancia de la libertad en los Estados Unidos, sino la función del país como paradigma de la libertad para otras naciones e individuos, lo que se aprecia posteriormente cuando Narbik arriba a los Estados Unidos huyendo de la guerra.

En estrecha conexión con la libertad se halla la democracia, considerada por Basco George como innata de los Estados Unidos, presente ya en su Constitución: "We, the people" [...]. When you understand those words, you understand what democracy is - a government "of the people, by the people, for the 
people”» (242). Del País Vasco asimismo se enfatiza su ancestral democracia, como lo expresa el padre de Narbik: «Ours is the oldest democracy of Europe. Guernica is our holy city. Our nation's song is Guernikako Arbola, The Tree of Guernica» (51). López señala al respecto que en numerosos artículos de la prensa nacionalista vasca de la década de 1940 se intenta probar que «los vascos son demócratas por su historia y por su práctica política actual y que son un pueblo maduro capaz de gobernarse a sí mismo» (59). Al presentar a Euskadi y Estados Unidos como naciones fundadas en la democracia, se busca subrayar el fuerte vínculo entre ambas. ${ }^{19}$

La mención a Gernika como ciudad sagrada de los vascos es una constante en la obra para remarcar la existencia de los fueros vascos, de la tradición democrática de Euskadi: «Ferdinand and Isabella swore by the stump of the old oak to protect Basque rights and privileges» (253). Posteriormente se alude al bombardeo de Gernika por la aviación nazi, cuando Narbik se halla ya exiliado en Idaho (294). La destrucción de Gernika se convierte para el nacionalismo vasco en el más claro ejemplo de agresión a la democracia. En el segundo número de la revista Basques de abril de 1943, titulado «Remember Guernica», se conecta el ataque de la villa vasca con el de Pearl Harbor para manifestar cómo Euskadi y Estados Unidos han sufrido embates similares a sus sistemas democráticos: «And the shrapnel which finished the treacherous job at Pearl Harbour was the same which challenged the civilized world to a death struggle over the stricken body of Guernica» (1). Con ello se intenta animar a los Estados Unidos a oponerse a Franco y apoyar al nacionalismo vasco. Basco George transmite la misma idea al señalar que la defensa de la democracia es un deber de todas las personas libres: «The future of democracy is the responsibility of every free people on earth» (103). ${ }^{20}$

Las banderas de Euskadi y Estados Unidos también se utilizan en la novela para resaltar las semejanzas entre las dos naciones. Cuando Narbik parte por primera vez hacia las montañas como pastor, identifica los colores de la ikurriña con el paisaje vasco: las colinas verdes, los tejados rojos de los caseríos y sus paredes blancas (61). De esta manera se conecta la bandera de Euskadi con su geografía, naturalizando dicho símbolo nacional. Posteriormente se relacionan los colores de la ikurriña con valores considerados intrínsecos de Euskadi: «I gazed at the flag. Its red stood for the blood of sacrifice. Its green stood for life. Its white cross stood for Christianity»(229). Basco George explica los

19 Así se explicitaba en agosto de 1944 en el número seis de la revista Basques, dedicado al tema de la democracia vasca: «Aside from other spiritual characteristics, we Basques have one very important tradition in common with the Anglo-Saxons: our democratic tradition. [...] And in comparing us with the Americans we can say that both nations, fundamentally, were "conceived in liberty"》(1).

20 En el número seis de la revista Basques de agosto de 1944 se solicitaba la ayuda de los Estados Unidos basándose en su sistema democrático: «The little Basque democracy has never lost its faith in universal democracy and less still in the powerful American democracy. [...] And if American generosity has time and again rebuilt the ruined monuments of Europe, we believe it will also help the Basques rebuild one of the most beautiful spiritual monuments of the Old World: the Basque Democracy» (15). 
colores de la bandera de Estados Unidos ofreciendo características nacionales parecidas, lo que lleva a Narbik a establecer similitudes entre las dos banderas: «I began to think again of the two flags. Red, white, and blue for the United States. Red, white, and green for Euzkadi. And the colors mean almost the same» (102). En palabras de Basco George, ambas representan naciones análogas por sus ideales democráticos: «Both are the flags of nations that have fought for democracy» (102).

Asimismo, las dos banderas se muestran como fuentes de protección y consuelo para sus respectivos ciudadanos. Cuando Narbik está convaleciente tras pelearse con un jabalí, la visión de la ikurriña le hace sentirse seguro y completo, mientras que Basco George también proclama que la bandera de Estados Unidos le protege. Las banderas se erigen aquí como símbolos celestiales que confortan a los miembros de la nación, mientras que las ideologías nacionalistas se presentan indisolublemente asociadas con el sentimiento religioso. De hecho, en la novela se interpreta que la ikurriña y la bandera de Estados Unidos contienen símbolos cristianos: la primera incluye la cruz blanca y la segunda, las estrellas blancas procedentes del cielo, similares a la estrella de Belén. El cristianismo se considera, por tanto, como un elemento fundamental de ambas naciones.

En relación con la religión, Narbik recuerda uno de los lemas de Sabino Arana, «All for Euzkadi and Euzkadi for God» (250). Como explica José Luis de la Granja, la consigna «Nosotros para Euzkadi y Euzkadi para Dios» se debía al rechazo que el fundador del nacionalismo vasco sentía por el liberalismo, asociado con España, y a su deseo de salvación celestial del pueblo vasco (2000: 30). Para Basco George, el cristianismo de Euskadi y Estados Unidos se halla firmemente asociado a sus valores de libertad y democracia: «You and I are Christians, Narbik. [...] We dedicate our lives to Jesus. So, too, we dedicate our lives to the democratic ideal of liberty. Only in democracies do we see Christ's message of good will to men at work» (103). En definitiva, ambas naciones se describen en la novela como modelos de democracias cristianas. Esta imagen podría servir para contrarrestar las reticencias existentes en la comunidad católica de Estados Unidos para ofrecer su apoyo al nacionalismo vasco. $^{21}$

\section{III.- EL DESEO DE GANAR: LA MASCULINIDAD VASCA}

Además de enfatizar las similitudes ideológicas entre Euskadi y los Estados Unidos, White Stars of Freedom presenta al protagonista vasco con unos valores masculinos semejantes a los de la masculinidad hegemónica de los Estados

21 El lehendakari Aguirre se lamentaba de que los católicos estadounidenses estaban a favor de Franco por su rechazo al comunismo y les instaba a percatarse de que el auténtico catolicismo es incompatible con la dictadura y la muerte: «Lo que cuesta trabajo comprender a estas alturas [...] es que se oiga a un ciudadano americano confundir lamentablemente civilización cristiana con campos de concentración, exilio y fusilamientos» (1992: 269). 
Unidos. Al tratarse de una novela de crecimiento, se muestra en detalle cómo Narbik se hace un hombre según los parámetros del nacionalismo vasco. Desde el segundo hasta el decimoctavo capítulo, la acción se desarrolla en el País Vasco rural desde 1933 hasta 1936, donde el protagonista trabaja como pastor desde los trece hasta los dieciséis años, adquiriendo diversos rasgos tradicionales de la masculinidad vasca: la fuerza física y mental para la superación de obstáculos, la lealtad, la laboriosidad, la independencia y el deseo de ganar. Las cualidades que Narbik manifiesta a medida que se hace un hombre no son exclusivas de la masculinidad vasca, sino extensibles a la mayoría de masculinidades nacionales. De esta manera, considero que Isasi y Denny construyeron a Narbik con características de la masculinidad vasca altamente valoradas y fácilmente transferibles a la sociedad americana para promover la aceptación del nacionalismo vasco y de los vascos nacionalizados en los Estados Unidos. De hecho, Douglass y Bilbao señalan que los emigrantes vascos en Estados Unidos poseían valores muy apreciados en la cultura americana, como su dedicación al trabajo, el ahorro y la higiene: «In this respect, Basques were as "American" as any other immigrant group, possibly more so than most» (3).

Como ha demostrado George Mosse, los nacionalismos crean desde sus orígenes una concepción determinada de la masculinidad y de la feminidad (1985: 16); es decir, preconizan las características ideales que los hombres y las mujeres de la nación deben poseer. Así, el hombre de la nación se construye con cualidades positivas tanto física como moralmente: su fuerza y atractivo físico van acompañados de la caballerosidad y virtud (Mosse 1996: 23). En el caso del nacionalismo vasco, Nerea Aresti ha analizado cómo para Sabino Arana la virilidad era una cualidad superior que él consideraba innata del pueblo vasco frente al español, al que describía como afeminado y embrutecido a la vez (2016: 121). Desde su perspectiva, el hombre vasco era el adalid de la nación y lo retrataba como varonil, honrado, limpio, respetuoso, trabajador, emprendedor, reservado y pacífico (Aresti 2017: 86). La mayoría de estas características se manifiestan en Narbik de una manera $u$ otra.

La portada del libro incluye una ilustración de Kurt Wiese en la que el protagonista encarna al hombre de la nación vasca, no solo por su atuendo tradicional con la boina y las alpargatas, sino sobre todo por su posición corporal erguida, la cual transmite serenidad, dominio de la situación e independencia (Fig. 1). Narbik se nos presenta en su oficio de pastor, rodeado de sus ovejas y de su perro Gau y mirando al horizonte rodeado de montañas. Así se produce una simbiosis entre su figura y el paisaje vasco. Como apunta Mosse, las montañas tienden a simbolizar la nación y su libertad, la estabilidad frente al cambio y virtudes valoradas por los nacionalismos como la dureza, la lucha y la lealtad (1990: 118). Al vivir en las montañas, estas cualidades se transfieren a Narbik, erigiéndose como prototipo del hombre vasco a pesar de su corta edad. 
Fig. I. NARbiK EN LA PORTAda de White StaRS of FreEdom

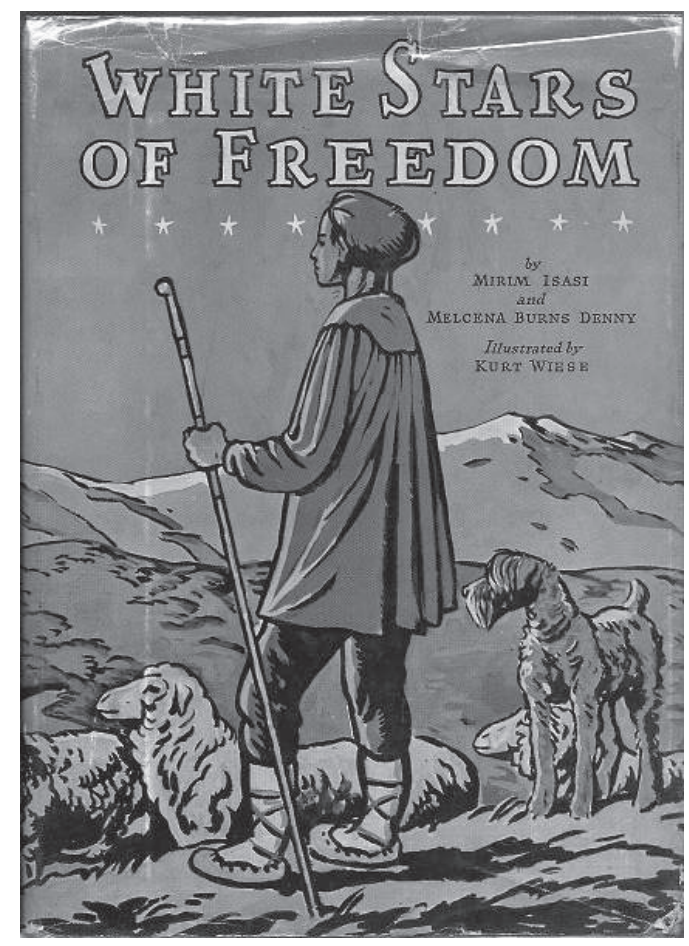

Desde el comienzo de la novela el protagonista muestra siempre respeto hacia sus mayores, estableciendo una estrecha conexión con su padre y su abuelo. La madre se encarga de las labores del hogar, mientras que el padre se ocupa del cuidado de las ovejas, siguiendo así la tradicional división del trabajo entre hombres y mujeres en el País Vasco rural (Bullen 2003: 69). El padre es asimismo el que toma las decisiones familiares, algo común en el caserío vasco (Valle 1985: 158). De esta manera, es él quien planea que Narbik se haga pastor y el que, cuando estalla la Guerra Civil, le da instrucciones para vender las ovejas en Francia e irse a Inglaterra. La descripción del padre acentúa sus atributos positivos, tanto en lo físico como en lo moral: «He was a strong, clear-thinking, practical man, straight-backed and handsome» (38). Actúa como el etxekojaun, como el cabeza de familia, lo que se aprecia sobre todo cuando participa en la competición de arrastre de bueyes (idi-probak) y consigue vencer a Valintin, quien había retado a los Aguirre y poseía unos bueyes más fuertes: «Father was the general of the day. He decided all moves in our family» (202). A través de su padre, Narbik aprende que la fuerza física no lo es todo y que debe ir acompañada de la astucia y la inteligencia. El padre se convierte en un modelo de conducta para el muchacho, como se aprecia en una ilustración incluida en la novela, en la que el padre junto a sus bueyes le mira alegre, demostrando sus expectativas de que Narbik continúe el legado familiar (Fig. 2). 
FIG. 2. NARBIK OBSERVANDO A SU PADRE CON LOS BUEYES

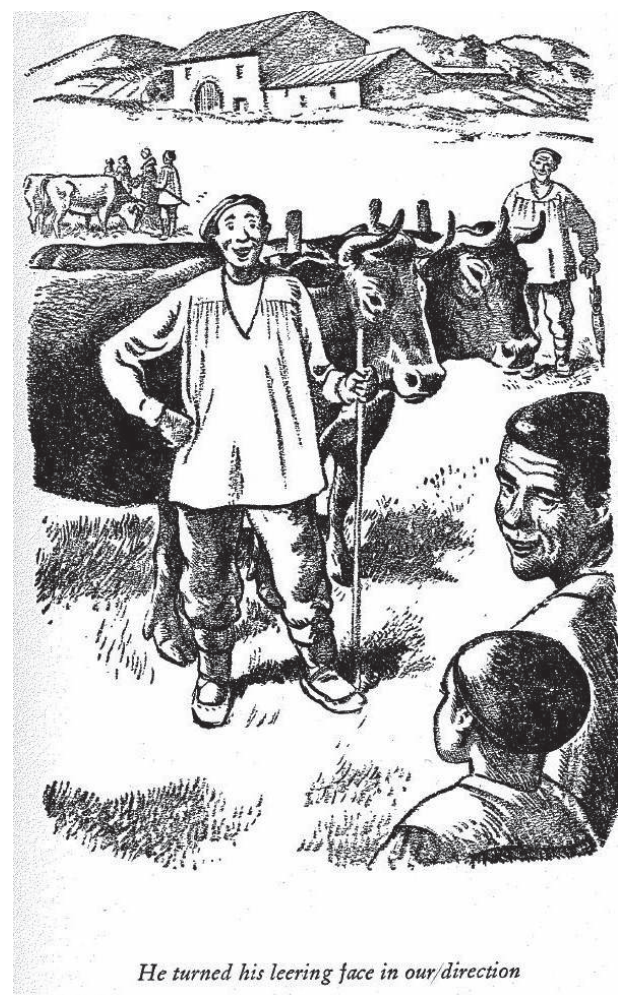

La conexión entre los hombres de la familia se subraya a lo largo de toda la obra, revelando la existencia de una clara patrilinealidad. Al hacerse pastor, Narbik sigue la tradición de su padre y su abuelo, quienes también se dedicaron al cuidado de las ovejas. Con su abuelo mantiene una estrecha relación y de él hereda la vara de pastor y posteriormente un txistu. El abuelo le relata historias de su juventud, transmitiéndole información sobre el pasado y las tradiciones de Euskadi. Narbik es consciente de que su nuevo oficio de pastor implica pertenecer a la comunidad de hombres de su familia y honrar su linaje: «I looked at my father and grandfather. It was then I realized for the first time that my affairs now rested among men» (44). Los hombres se presentan así como los miembros activos y principales impulsores de la nación.

Además del padre y del abuelo, Basco George actúa como maestro de Narbik, convirtiéndose en una persona más de su familia. Narbik le conoce por primera vez en las montañas cuando Basco George visita su País Vasco natal tras llevar doce años viviendo en Idaho, donde tiene un rancho. Si del padre y del abuelo Narbik aprende las tradiciones vascas, Basco George lo instruye sobre los Estados Unidos, hablándole sobre los valores de esa nación y las oportunidades que ha encontrado allí. También le enseña a disparar un rifle, le 
da lecciones de vida como el no odiar para poder ser libre y le cuida tras ser herido por un jabalí. Posteriormente, cuando Narbik se exilia, se ocupa de acogerle y ayudarle en los Estados Unidos. En definitiva, actúa como un maestro y una figura paterna para el protagonista, llegándosele a comparar con Cristo: «He seemed Christlike to me» (228). Basco George se presenta como el salvador o mesías de Narbik al descubrirle Estados Unidos y ayudarle a conseguir su ciudadanía. Son los hombres mayores —el padre, el abuelo y Basco Georgequienes le enseñan a Narbik a ser un hombre vasco y estadounidense y quienes confirman su masculinidad y crecimiento. De esta manera, le acogen en la camaradería masculina de la nación, la cual se construye como un proyecto masculino.

El padre y el abuelo inician a Narbik en el oficio de pastor, lo que se puede interpretar como un rito de paso a la masculinidad vasca. Como indica Leo Braudy, ser un hombre es un acto intencionado, celebrado por la comunidad, y por este motivo la iniciación masculina es compleja y pública (2003: 19). David Gilmore señala que la masculinidad se concibe como un premio que el joven debe ganar alejándose de la infancia y del apego a la madre (1990: 29). Por eso Narbik se separa de su familia y su hogar y parte solo hacia las montañas. Su padre indica claramente que su trabajo como pastor constituirá una prueba de masculinidad: «Fifty [sheep] will be enough to prove your manhood» (39). También le advierte de posibles dificultades que padecerá, como la nostalgia y la soledad, pero que le posibilitarán convertirse en un hombre: «He must go forth toward manhood. His judgement will grow with the decisions he must make alone» (52). Su entrada a la masculinidad supondrá al mismo tiempo su pertenencia a la fraternidad nacional: «Our country has need of sons who can master hardships» (42).

Narbik desea demostrar a su familia su valía como hombre y por eso le pide a su padre permanecer en las montañas durante todo un año. Tras la primera noche como pastor, se siente orgulloso por realizar un oficio asignado a los varones: «Now I was doing man's work [...]. I felt wide awake at last, and full of pride and importance» (72). Cuando regresa a su caserío después de un año, recibe el respeto de sus familiares y vecinos por haber realizado bien su trabajo: «I was treated almost as if I were a man, because I had been faithful to my trust» (126). Su entrada al mundo de los hombres se ve confirmada por su desarrollo físico al hacerse más fuerte y alto. Así muestra su admiración hacia él el Padre Zabola tras percibir su cambio corporal: «What muscle! You've grown a head taller since I saw you last year. [...] You look hard as oak» (133). Ya antes de partir como pastor, se nos describe a Narbik como ancho y fuerte, y su padre reconoce su destreza física en los deportes rurales vascos (37-38). La fuerza de los hombres es especialmente importante para los nacionalismos porque simboliza el vigor de la nación y su capacidad de lucha. En el País Vasco rural recibe el nombre de indarra y es altamente valorada porque resulta necesaria en las labores del campo (Bullen 2003: 119). Aunque la indarra no se considera exclusiva de los hombres, William Douglass y Joseba Zulaika indican que sirve como señal de su virilidad (2007: 262). 
Además de la fuerza física, Narbik manifiesta su capacidad para enfrentarse solo a situaciones difíciles y superar diversos obstáculos que se le presentan durante su estancia en las montañas. Como comenta Timothy Beneke, afrontar circunstancias que impliquen dolor físico o psicológico es una manera en la que los hombres prueban su masculinidad (1997: 36). Así, Narbik debe encarar contrariedades como la muerte de una de sus ovejas al recibir una coz de una mula, la pérdida de otra oveja a la que tiene que matar tras ser herida por su perro, el robo de lana por parte de unos gitanos, una tormenta fuerte y la nostalgia de casa. Sin embargo, la mayor dificultad que encuentra es el ataque de un jabalí al que consigue matar tras una ardua pelea en la que le ayudan sus dos perros (Fig. 3). Este episodio, que se narra con detalle, resulta relevante porque refleja no sólo la robustez física de Narbik, quien se recupera de sus heridas tras un periodo enfermo, sino también su fortaleza mental, ya que debe enfrentarse a la muerte de su perro fiel, que se sacrificó por salvarle.

Fig. 3. NARBIK y SUS PERROS, PELEANDO CON EL JABALí

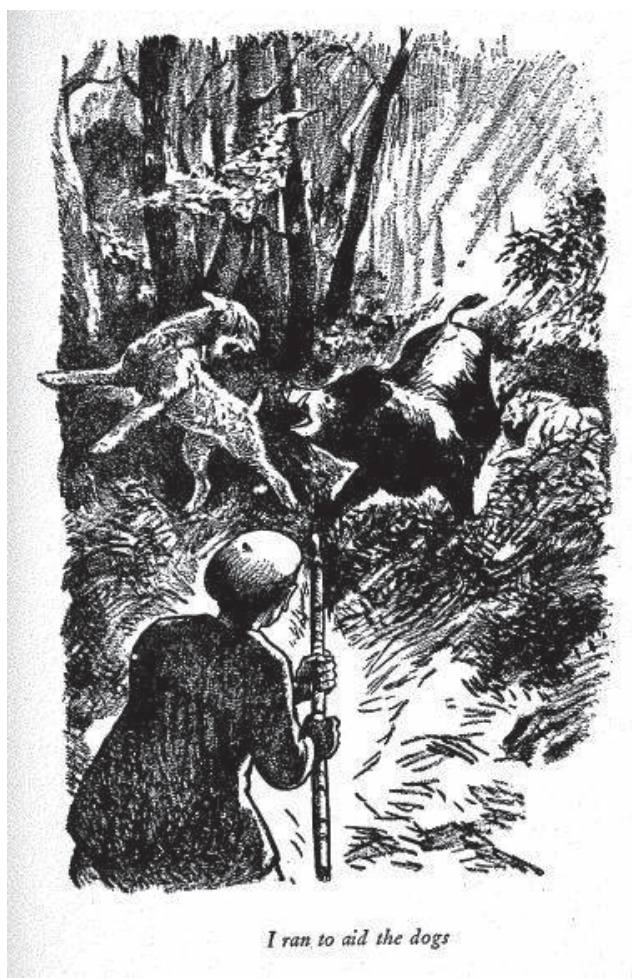

A través de estas situaciones difíciles el protagonista va aprendiendo diferentes lecciones que moldean su carácter. Él mismo narra explícitamente estas enseñanzas, lo que aumenta el tono didáctico de la novela. Por ejemplo, al 
morir una de las ovejas, se percata de que las desgracias pueden suceder en cualquier momento: «I had learned a dismaying truth - disaster can come without warning» (82). También aprende a no dejarse engañar por otras personas, a prestar atención a su trabajo y no distraerse e incluso a soportar el dolor físico. A pesar de estos infortunios, Narbik revela en todo momento su carácter responsable y trabajador, algo que la doctrina nacionalista vasca consideraba típico del hombre vasco (Aresti 2016: 125). Él enfatiza la lealtad como uno de sus principios, es decir, el cumplimiento del deber, de lo que se espera de él y de aquello a lo que se ha comprometido: cuidar las cincuenta ovejas que su padre le ha asignado. Narbik considera esta cualidad como intrínseca al ser vasco: «To be Basque is to be faithful» (39). Tradicionalmente los vascos han tenido la fama de cumplir siempre sus promesas y ser fieles a su palabra. Para el hombre vasco esta conducta constituye su honor y honradez personal, y por ello en los Estados Unidos a los pastores vascos se les estimaba como personas de confianza (Vaczi 2015: 85).22

Por medio de su trabajo como pastor, Narbik también adquiere otros rasgos considerados tradicionalmente positivos en el hombre vasco y que al mismo tiempo forman parte de la masculinidad normativa de muchas otras culturas: la independencia y la capacidad de liderazgo y de toma de decisiones. La soledad que experimenta le hace valerse por sí mismo y ser capaz de resolver los imprevistos que le suceden. Su independencia personal como vasco se puede conectar con la autonomía o el deseo de libertad de Euskadi, como se ha comentado anteriormente. Además, demuestra que es capaz de dirigir las ovejas y dar órdenes que obedezcan sus perros. Significativamente, se describe a su perro Gau como un soldado al que comandar: «Gau listened, standing like a soldier before me. [...] I'll have to be a good shepherd, I thought, and make Gau realize fully that I am master» (76).

Narbik también toma decisiones por sí mismo y aunque se equivoque en algunas ocasiones, aprende de sus errores. En este sentido, es relevante mencionar el aspecto simbólico y cristiano que el oficio de pastor adquiere en la obra como guía de la humanidad. En diversas ocasiones se describe a Dios como Pastor — «Our heavenly Shepherd» (90)—y Basco George califica a Narbik y a sí mismo como los pastores de la libertad (241). Con esta metáfora, se indica que ambos luchan por el ideal de libertad, lo que para las autoras significa que Narbik se aliste como voluntario en la Segunda Guerra Mundial. A pesar de la doctrina patriótica y cristiana que encierra esta imagen, con ella Isasi y Denny contraponen la estigmatización social que tenía el oficio de pastor (Douglass + Bilbao 2005: 345), le dan prestigio y lo envuelven dentro de una masculinidad mesiánica.

Además de capacidad de liderazgo, Narbik posee otra cualidad que adquiere al jugar un partido de pelota con el Padre Zabola como compañero: el deseo de ganar. Como afirma el narrador, la pelota se considera el deporte nacional

22 En Basque Girl se insiste en la misma idea, ya en el título del último capítulo: «To Be Basque Is to Be Faithful». Para Erena, ser leal es comportarse moralmente, lo que le supone alejarse del prometido de su amiga inglesa. 
vasco: «In Basque land every wall is a court; every Basque boy, not a posible president, but a possible pelota champion» (134). Tradicionalmente los pelotaris siempre han sido varones y, como indica Olatz González-Abrisketa, una convicción reiterada es que jugar a la pelota refuerza física y moralmente a los hombres (2013a: 97). Para Narbik, el partido supone una prueba de su masculinidad y de su estatus en la nación vasca: «I will do my best. I will try not to disgrace the Basque nation» (135). Los juegos competitivos entre hombres son comunes en la cultura vasca. Además de la pelota, Joseba Zulaika menciona otras modalidades dentro del joko como las carreras, las competiciones de bertsolaris y el mus (1988: 172). ${ }^{23}$ El partido de Narbik atrae a muchos espectadores, entre los que están sus familiares y Valintin Alola. Este último intenta constantemente minar el ánimo de Narbik, burlándose de él e insultándole cada vez que comete un error. De esta manera, aunque no juegue contra Valintin, el partido supone una competición entre ellos dos y sus respectivas familias, enfrentadas desde hace tiempo.

Por medio del Padre Zabola, que no se rinde en el juego a pesar de herirse la mano, Narbik se percata de la importancia de poseer el deseo de ganar y es entonces cuando mejora su juego: «I felt the will to win! My strength doubled» (147). Aunque se le hincha la mano, Narbik decide continuar jugando y finalmente el Padre Zabola y él ganan el partido. El joven demuestra su capacidad de soportar el dolor y no rendirse, lo que, de acuerdo a González-Abrisketa, es lo que hace a un pelotari ser respetado por el público (2013b: 120). Con la victoria, Narbik consigue derrotar a Valintin, reforzar el honor familiar y probar su masculinidad. Sin embargo, su mayor logro es la lección que aprende: cómo se consiguen superar los obstáculos si se tiene voluntad de ganar. Más tarde, Basco George se lo confirma cuando le relata su historia exitosa de emigrante en los Estados Unidos: «I went there, Narbik, without money and without the language. But I took with me something that you have too. The will to win. [...] You must have it when you play the game of life» (240). Con el estallido de la Guerra Civil, Narbik decide seguir los pasos de Basco George y exiliarse en los Estados Unidos.

\section{IV.- EL EXILIO COMO REFORZADOR DE LA MASCULINIDAD Y LA IDENTIDAD TRANSNACIONAL}

El exilio de Narbik se presenta como positivo y beneficioso en su vida porque le ofrece oportunidades para desarrollarse personal y profesionalmente y para vivir en libertad. Narbik llega a Estados Unidos tras pasar por Inglaterra, donde su madre y su hermana Mirentxu se han refugiado en casa de la tía Petra. Al morir la madre en Londres, Narbik se va con Mirentxu a los Estados Unidos y reside en el rancho de Basco George en Idaho. Posteriormente trabaja como

23 Este tipo de competiciones entre hombres vascos y el modelo tradicional de masculinidad que representa han sido objeto de parodias en la época contemporánea en el programa Vaya Semanita, de Euskal Telebista (González-Allende 2015: 25). 
pastor en California y en el último año se muda a San Diego para trabajar en un zoo y estudiar por las noches.

No se habla mucho de la vida cotidiana de Narbik en los Estados Unidos, ya que solo el primer y los dos últimos capítulos de la novela se enfocan en las experiencias del protagonista en su nuevo país y narran mayormente su ceremonia de ciudadanía. Esto mismo sucede en otras obras escritas por nacionalistas vascos en el exilio en los Estados Unidos, como Basque Girl, de Isasi y Yanqui hirsutus, de Sota, en las que apenas se menciona nada de la realidad de los protagonistas en tierras americanas. Según confirman Isasi y Denny en la sección de agradecimientos, de hecho, fueron los editores del libro quienes les instaron a mostrar la vida de Narbik en los Estados Unidos (307), ya que parece que, en una primera versión, la narración terminaba con el viaje del joven al exilio. La ausencia de detalles sobre las experiencias del protagonista en el país americano - lo que se aprecia asimismo en la no inclusión de ninguna ilustración de él en los Estados Unidos - puede deberse a que las autoras no querían mostrar las dificultades que padecen los exiliados y emigrantes para adaptarse a la nueva sociedad y arriesgarse así a dar una imagen negativa del país, puesto que el objetivo de su novela es ensalzar los Estados Unidos como tierra de libertad.

La obra sólo apunta brevemente algunas circunstancias adversas que padece Narbik en los Estados Unidos. A su llegada a Idaho, siente remordimientos por no haber luchado por Euskadi en la guerra mientras su padre y Begoña aún permanecen allí. Posteriormente, cuando trabaja como pastor en California, su jefe resulta arisco y las condiciones del trabajo duras: «I found the herder a silent man, and his dog not friendly. [...] Due to his failing strength, the old Scot preferred to tend camp and let me herd the large flock of desert sheep» (296). En sus comienzos en los Estados Unidos, Basco George también tuvo similares problemas con uno de sus jefes, quien llegó a matar a su perro. Douglass y Bilbao señalan al respecto que en los Estados Unidos los pastores vascos debían ocuparse de rebaños de ovejas mucho más numerosos que en Euskadi y que el clima y los depredadores provocaban que su trabajo requiriera dedicación completa (2005: 224). También mencionan los riesgos que padecían los pastores vascos al hallarse aislados y solos, mayormente la inestabilidad emocional, la locura e incluso el suicidio (2005: 299). La novela omite en gran parte esta dura realidad de los pastores vascos. Lo que sí manifiesta son los desencuentros generacionales entre Narbik y su hermana Mirentxu, que tiene entonces doce años, debido a su distinta concepción de la identidad nacional. Mirentxu desea adaptarse y pasar desapercibida en la cultura estadounidense porque se siente avergonzada de que en la escuela la maestra no pueda pronunciar ni su nombre ni su apellido. Por ello parece rechazar su origen vasco, adopta el nombre de «Mary» y le recrimina a Narbik por vestirse con su atuendo vasco de fiesta para su ceremonia de ciudadanía.

A pesar de estas dificultades, Narbik considera su exilio como positivo, no como una experiencia trágica, y tras cinco años viviendo en Estados Unidos, no da muestras de nostalgia del País Vasco. Su masculinidad no se ve afectada negativamente por el exilio, lo que sí les sucede a numerosos hombres que viven desplazados (González-Allende 2018: 4). Su destierro, ya desde su entra- 
da a los Estados Unidos, se describe como una liberación. Antes de partir al exilio, su madre le lee un poema sobre la Estatua de la Libertad en el que se representa a los Estados Unidos como símbolo de salvación de los emigrantes y exiliados menesterosos: «Send these, the homeless, the tempest-tost to me; I lift my lamp beside the golden door» (292). La reacción emocionada de Narbik y Mirentxu al ver la Estatua de la Libertad desde el barco en el que entran al país reitera esta concepción de Estados Unidos como tierra de promisión: " "Liberty lifts her lamp", I answered, filled with sudden happiness. "She welcomes us, Mirentxu”»(293). En otras obras del nacionalismo vasco en Estados Unidos como Yanqui hirsutus y De Guernica a Nueva York se encuentra la misma idea.

En la novela Estados Unidos se presenta bajo el manido tópico de ser el país de las oportunidades. Así se lo indica Basco George a Narbik: «the United States is a land of opportunity» (240). Las mejoras materiales que logra Basco George, entre ellas un rancho con miles de ovejas, demuestran cómo la emigración o el exilio pueden reforzar la masculinidad de los hombres desplazados al posibilitarles el éxito económico. Narbik desea seguir el ejemplo de su mentor: «Some day I would own a thousand sheep. I would be a respected citizen» (20). Por ello va a la escuela por las noches y ha progresado profesionalmente al trabajar como cuidador de animales en un zoo: «There are good jobs here. I get free schooling here, even now that I am grown. A hard-working man has an opportunity to get along in this country» (33). De esta manera, el exilio le ha posibilitado mayores ocasiones de ascenso social y sentirse más válido como hombre.

La confirmación de la masculinidad de Narbik, empero, se produce cuando se convierte en ciudadano estadounidense. Si el abandono de su casa para trabajar como pastor se presentaba como su primer rito de masculinidad, posteriormente su ciudadanía americana se considera como su entrada definitiva al mundo de los hombres adultos: «Back of me was a life that had held both joy and sorrow. It was the life of a shepherd boy. Ahead of me was manhood-manhood in the country of my own choosing» (35). Al abrirse y cerrarse la novela desde el momento presente enmarcando la narración del pasado del protagonista, se da a entender que su vida en el País Vasco le ha preparado para formar parte de los Estados Unidos: «I had been thinking of the tests and trials of manhood I had gone through as a young shepherd. [...] I saw that Begona was right when she said my whole life had been a preparation for this day» (300). Por lo tanto, los valores de la masculinidad vasca, al resultar similares a los de la masculinidad en los Estados Unidos, le han posibilitado llegar a convertirse en ciudadano estadounidense.

La novela enfatiza que ser ciudadano de los Estados Unidos implica una lealtad política exclusiva para ese país. Basco George se lo explica a Narbik cuando éste todavía se halla en el País Vasco: «If they are citizens of the United States, they are not Basques, they are Americans. That is their home. No man can have two countries» (245). Basco George se identifica exclusivamente como estadounidense: «Allegiance is something you can't divide. I am an American» (103). Por su parte, Narbik se convierte en ciudadano estadounidense y se enlistará en su ejército porque considera que su nación originaria, Euskadi, 
se ha perdido y debe encontrar una nueva, Estados Unidos, en la que pueda ser libre y luchar por la libertad de los demás: «I, whose Basque flag was no more, would this day have a country I could love and serve» (301). La muerte de su madre en Inglaterra puede simbolizar precisamente la pérdida de la nación vasca, ya que solo cuando muere ella, Narbik y su hermana pueden partir para los Estados Unidos.

Como Euskadi ha caído bajo la dictadura franquista, el padre le insta a Narbik a que se convierta en ciudadano estadounidense y luche por Estados Unidos para la defensa de la democracia en el mundo: "If little democracies fall, strong democracies must make themselves stronger. Add your strength, your faithfulness, to that of the United States, and it will not be lost» (295). La misma idea ofrece Begoña, quien también planea hacerse ciudadana de los Estados Unidos: «Our Basque flag, with its motto, Invincible, belongs to the past [...]. The democratic ideal of liberty is the same the world over» (298). Estos comentarios de los personajes pueden hacer pensar, como indica Estibalitz Ezkerra, que se transmite la idea de que se debe renunciar a una cultura para integrarse en la otra (2012: 347). Sin embargo, considero que en el caso de Narbik la nueva lealtad política no implica el abandono de la cultura originaria.

Así, Narbik insiste en mantener las costumbres vascas en los Estados Unidos, a diferencia de su hermana menor: «I too wanted to be American. But instead of wishing to shed everything about me that was Basque, I wanted to bring all that was good as a gift to my beloved new land» (29). Por este motivo, se niega a cambiarse el nombre, algo que sí hizo Basco George, cuyo nombre originario era Gorka Echarren. Otra diferencia significativa entre ambos es que Basco George se casó con una mujer americana que no podía aprender el euskera, mientras que Narbik planea contraer matrimonio con una joven vasca exiliada que vive en Idaho, logrando de esta forma la continuación de la nación vasca en el destierro. Es posible que esta divergencia entre los dos personajes se deba a que Basco George llegó a Estados Unidos como emigrante, de manera voluntaria, mientras que Narbik es un exiliado que ha sido forzado a abandonar su nación debido a una dictadura.

En realidad, Narbik presenta una identidad transnacional vasco-americana. El transnacionalismo en las personas desplazadas implica que su vida diaria y sus identidades públicas se configuran en relación a más de una nación. Se han asentado en el país en el que residen, pero al mismo tiempo mantienen conexiones con su tierra de origen (Schiller + Basch + Blanc 1995: 48). Begoña expresa elocuentemente la identidad transnacional en un discurso que da en Gernika: «We are thankful with all our hearts for our brave past. But it must not drag us back from growth. Growth means a lift, a release. For some of us may mean a transplanting» (262). Begoña defiende aquí la posibilidad de abandonar Euskadi y de no seguir las tradiciones vascas para poder crecer personalmente, pero sin que ello implique perder sus raíces vascas. ${ }^{24}$

${ }^{24}$ A diferencia de Narbik y Begoña, la protagonista de Basque Girl se proclama únicamente vasca al final de la novela: «Devotion to Home, Pride of Race, Love of Tradition -I am Basque. Gora Euzkadi!» (249). Su identidad exclusivamente vasca se 
Esta realidad transnacional se revela en los títulos de la propia novela, escritos tanto en inglés como en euskera: «Basque Home / Basetxe», «To Go Forth /Bide-Egin» «Grief / Onazez», etc. El euskera se utiliza a menudo a lo largo de la obra, especialmente en los nombres propios de los personajes (Mirentxu, Begoña, Imanol, Jaun Alola) y de los animales (los perros Beltz, Gau y Zuri, los bueyes Zori y Gaizto), las canciones y tradiciones populares (el «BogaBoga», el «Guernikako Arbola», aurresku, txistu) y el paisaje vasco (la cima llamada «Emakume», el término pilist-palast para referirse al sonido de un arroyo). A veces se ofrecen explicaciones lingüísticas sobre palabras en euskera: «I thought with delight of the Basque word, lurrun, which means the earth's living breath» (183). El uso del euskera en la narración que el protagonista realiza desde su presente en los Estados Unidos revela la importancia emocional que su lengua nativa encierra para él. El euskera se conecta especialmente con la figura de su abuelo, quien le insta a hablar siempre en ese idioma: "Call your beret by its Basque name, Narbik”. "Txapel!", I laughed. "My pants are parkak, my shirt alkondara” (129). Cuando su abuelo fallece, Narbik rememora su palabra preferida, eresoinka, y su deseo de que sea grabada en su lápida: " "Eresoinka!", he exclaimed. "The most beautiful word in the Basque language. It is a combination of words that never should be used except by poets. It means singing voices and dancing feet" " (178). No parece casual que precisamente se llamara Eresoinka el grupo de coros y danzas vascos que realizó numerosas representaciones en Europa entre 1937 y 1939 para difundir la causa vasca.

Además, el euskera se erige como símbolo de la identidad y de la nación vascas. Así lo expresa el abuelo del protagonista: «the soul of a nation lives in its language! Help keep our language alive, Narbik» (129). En la novela se insiste en la originalidad y el carácter ancestral del euskera y cómo, al ser hablado solo por los vascos, sirve para guardar sus secretos. Sin embargo, también se enfatiza que el euskera se halla en peligro debido al gobierno reaccionario de España, el cual prohíbe su uso y obliga a hablar en castellano en las fiestas y reuniones populares. Por lo tanto, la lucha por la libertad de Euskadi se encuentra irremisiblemente unida a la de su idioma: "Without the language, we possess no country, no laws, no liberty» (256). Para las autoras del libro, al igual que para su protagonista, el euskera es ante todo la lengua de los vascos y, a pesar de su adaptación a los Estados Unidos, su mantenimiento resulta una parte imprescindible de su identidad transnacional.

White Stars of Freedom es una novela didáctica y propagandística a varios niveles: mayormente promueve una imagen idealizada de los Estados Unidos como país culmen de la libertad y la democracia que acoge a los exiliados o emigrantes de otras naciones y que les posibilita desarrollarse personal y profe-

manifiesta en la portada de la novela, donde aparece una fotografía de la propia autora vestida con el traje tradicional vasco, sentada y sonriendo, delante de una ikurriña con el emblema de Arana, «Jaun Goikua eta legi zaŕa» («Dios y las leyes viejas»). Utilizando la alegoría de la mujer-nación, la autora se presenta aquí como símbolo de la nación vasca en el exilio. 
sionalmente. Asimismo, ofrece una visión bucólica del País Vasco, enfatizando sus tradiciones ancestrales, su historia de autonomía, su idioma único y sus valores morales y familiares. Al tratarse de una obra juvenil, también transmite un modelo de comportamiento por medio del protagonista, cuyo crecimiento dentro de los parámetros normativos de la masculinidad vasca ejemplifica cualidades viriles apreciables en numerosas culturas como la estadounidense. Especialmente relevantes son su dedicación al trabajo, su motivación para superar las dificultades y no rendirse, su respeto a los mayores, su independencia y su entrega para luchar por su nueva nación como miembro de su ejército. Por lo tanto, es una obra que podría apelar a numerosos tipos de lectores para lograr diversos posibles objetivos: la valoración en Estados Unidos de la cultura vasca, la adhesión de las personas de origen vasco al nacionalismo vasco, el apoyo político de los Estados Unidos a la causa nacionalista vasca, el fomento de la naturalización y del amor al país entre los extranjeros que viven en los Estados Unidos y la promoción del patriotismo y del alistamiento de estadounidenses en el ejército.

La fecha de publicación de la novela, durante la Segunda Guerra Mundial, explica su componente ideológico a favor de los Estados Unidos, pero el patriotismo americano y especialmente su contenido nacionalista vasco se entienden si la situamos dentro del pensamiento y actuación del nacionalismo vasco en el exilio en los Estados Unidos. Al igual que Sota y Aguirre, Isasi y Denny enfatizan la libertad, la democracia y el cristianismo de Euskadi, así como las similitudes de valores y carácter entre Euskadi y Estados Unidos para recabar apoyos del gobierno en contra de la dictadura franquista. La identidad transnacional que encarna el protagonista al final de la novela simboliza la unión fraternal entre ambas naciones y la posibilidad de compaginar la lealtad política a los Estados Unidos con el mantenimiento de la cultura vasca. En el exilio Narbik puede crecer personal y profesionalmente porque cuando llega a Estados Unidos trae consigo los valores normativos de la masculinidad vasca que compaginan bien con la sociedad estadounidense. Al naturalizarse como ciudadano estadounidense se convierte en un hombre de su nuevo país, lo que supone para él unirse al ejército y arriesgar su vida en la batalla. Su transformación de pastor vasco a soldado americano implica el paso de la lealtad al padre a la lealtad a la nación, pero en ambos casos se revela cómo la masculinidad normativa se entiende como el cumplimiento del deber (familiar, social y nacional) y la demostración de la valía del hombre por medio de la acción y la superación de continuas pruebas. Si el ser pastor le abrió las puertas a la masculinidad en Euskadi, el ser soldado le confirmará como hombre estadounidense.

\section{BIBLIOGRAFÍA}

Aguirre, A. + San Sebastián, K. (2018) Newyorktarrak: Origen de la comunidad vasca de Nueva York, 1880-1955, Vitoria-Gasteiz, Gobierno Vasco.

Aguirre, J. A. (1992) De Guernica a Nueva York, pasando por Berlín, Bilbao, Ekin. 
Aguirre, J. A. (1998) Diario de Aguirre, ed. I. Egaña, Tafalla, Txalaparta.

Álvarez Gila, O. (2015) «Etnicidad, geografía y folclore en la construcción del estereotipo del inmigrante vasco en el cine norteamericano», Migraciones trans-atlánticas: desplazamientos, etnicidad y políticas, eds. E. González Martínez + R. González Leandri, Madrid, Catarata, pp. 175-97.

Álvarez Gila, O. (2016) «La dificultad de representar una inmigración invisible: Los vascos en el cine de Estados Unidos», Movimientos, trânsitos \& memórias: temas e abordagens, eds. É. Sarmiento + M. Pinheiro de Carvalho + P. Flier, Niterói, Universo, pp. 492-503.

Aresti, N. (2014) «De heroínas viriles a madres de la patria. Las mujeres y el nacionalismo vasco (1893-1937)», Historia y Política, 31, pp. 281-308.

Aresti, N. (2016) «El langile respetable. Masculinidad, moral y trabajo en el nacionalismo vasco», ¿La España invertebrada? Masculinidad y nación a comienzos del siglo XX, eds. N. Aresti + K. Peters + J. Brühne, Granada, Comares, pp. 119-35.

Aresti, N. (2017) «El gentleman y el bárbaro. Masculinidad y civilización en el nacionalismo vasco (1893-1937)», Cuadernos de Historia Contemporánea, 39, pp. 83-103.

Ascunce Arrieta, J. Á. (1999) «Exilio vasco y cultura», Ínsula, 627, pp. 5-8.

Ascunce Arrieta, J. Á. (2000) «La cultura del exilio vasco en castellano». Memoria del exilio vasco, ed. E. Palacios Fernández, Madrid, Biblioteca Nueva, pp. 71-97.

Bañales-Atxirika, V. (2015) Literary Portraits of Basque-American Women: From Shadow to Presence, dissertation at the University of the Basque Country.

«Basque Democracy. Editorial» (1944) Basques: Bulletin of the Basque Delegation in the USA, 6, p. 1.

Beneke, T. (1997) Proving Manhood: Reflections on Men and Sexism, Berkeley, University of California Press.

Braudy, L. (2003) From Chivalry to Terrorism: War and the Changing Nature of Masculinity, New York, Alfred A. Knopf.

Bullen, M. (2003) Basque Gender Studies, Reno, University of Nevada Press.

Douglass, W. + Bilbao, J. (2005) Amerikanuak: Basques in the New World, Reno, University of Nevada Press.

Douglass, W. + Zulaika, J. (2007) Basque Culture: Anthropological Perspectives, Reno, Center for Basque Studies.

Etulain, R. (1977) «The Basques in Western American Literature», AngloAmerican Contributions to Basque Studies: Essays in Honor of Jon Bilbao, Reno, Desert Research Institute, pp. 7-18. 
Ezkerra, E. (2012) «Other Basque Literatures», Basque Literary History, ed. M. J. Olaziregi, Reno, Center for Basque Studies, pp. 329-50.

Gilmore, D. (1990) Manhood in the Making: Cultural Concepts of Masculinity, New Haven, Yale University Press.

González-Abrisketa, O. (2013a) «Cuerpos desplazados: Género, deporte y protagonismo cultural en la plaza vasca», Revista de Antropología Iberoamericana, 8.1, pp. 83-110.

González-Abrisketa, O. (2013b) Basque Pelota: A Ritual, an Aesthetic, Reno, Center for Basque Studies.

González-Allende, I. (2015) «The Basque Big Boy? Basque Masculinities in Vaya Semanita», Journal of Iberian and Latin American Studies, 21.1, pp. 19-37.

González-Allende, I. (2016a) «José Ángel Ascunce Arrieta y la pluralidad del exilio vasco», El exilio vasco: Estudios en homenaje al Profesor José Ángel Ascunce Arrieta, ed. I. González-Allende, Bilbao, Universidad de Deusto, pp. 11-27.

González-Allende, I. (2016b) «Estados Unidos como patria de redención: El exilio del nacionalismo vasco en Yanqui hirsutus, de Manuel de la Sota», Cuadernos de ALDEEU, 30.1, pp. 13-34.

González-Allende, I. (2018) Hombres en movimiento: Masculinidades españolas en los exilios y emigraciones, 1939-1999, West Lafayette, Purdue University Press.

Granja Sainz, J. L. de la (2000) El nacionalismo vasco (1876-1975), Madrid, Arco-Libros.

Irujo, X. (2012) Expelled from the Motherland: The Government of President José Antonio Agirre in Exile, 1937-1960, Reno, Center for Basque Studies.

Isasi, M. (1940) Basque Girl, Glendale, Griffin-Patterson.

Isasi, M. + Denny M. B. (1942) White Stars of Freedom, Chicago, Albert Whitman.

López, E. (1977) El nacionalismo vasco en el exilio, 1937-1960, San Sebastián, Txertoa.

Mosse, G. L. (1985) Nationalism and Sexuality: Respectability and Abnormal Sexuality in Modern Europe, New York, H. Fertig.

Mosse, G. L. (1990) Fallen Soldiers: Reshaping the Memory of the World Wars, New York, Oxford University Press.

Mosse, G. L. (1996) The Image of Man: The Creation of Modern Masculinity, New York, Oxford University Press.

Mota Zurdo, D. (2012) «Estrategias políticas vascas. La Delegación del Gobierno Vasco en Nueva York ante la ONU y el Plan Marshall (1945-1950)», No 
es país para jóvenes, ed. Alejandra Ibarra Aguirregabiria, Vitoria-Gasteiz, Universidad del País Vasco, pp. 1-17.

Mota Zurdo, D. (2017) «Un sueño americano. El Gobierno vasco en el exilio y los Estados Unidos (1937-1979)», Bulletin d'Histoire Contemporaine de l'Espagne, 51, pp. 296-301.

Olaziregi, M. J. (2010) «Las representaciones de la diáspora en la literatura infantil y juvenil vasca», Anuario de Investigación en Literatura Infantil y Juvenil, 8, pp. 111-21.

Palacios Fernández, E. (2000) «Pórtico», Memoria del exilio vasco, ed. E. Palacios Fernández, Madrid, Biblioteca Nueva, pp. 9-17.

«Remember Guernica. Editorial» (1943) Basques: Bulletin of the Basque Delegation in the USA, 2, p. 1.

Río Raigadas, D. (1999). «The Treatment of Basques in Modern Western Literature», ES: Revista de Filología Inglesa, 22, pp. 45-52.

Río Raigadas, D. (2002) «Escritores de origen vasco en los Estados Unidos: Una visión panorámica», XV Congreso de Estudios Vascos: Ciencia y cultura vasca, y redes telemáticas, Donostia, Eusko Ikaskuntza, pp. 675-80.

Saitua, I. (2018) «The Best Sheepherder. The Racial Stereotype of Basque Immigrants in the American West Between the End of the Nineteenth and the Beginning of the Twentieth Centuries», Historia Contemporánea, 56, pp. 81-119.

San Sebastián, K. (1991) The Basque Archives: Vascos en Estados Unidos (1938-1943), Donostia-San Sebastián, Txertoa.

San Sebastián, K. (2014) Exilio vasco en América, Vitoria-Gasteiz, Gobierno Vasco.

Sanz Goikoetxea, E. + Álvarez Gila, O. (2010) «La Delegación en Nueva York (1938-1966)», Delegaciones de Euskadi (1936-1975). Antecedentes históricos de los siglos XVI al XIX, origen y desarrollo, Vitoria-Gasteiz, Gobierno Vasco, pp. 169-92.

Schiller, N. G. + Basch, L. + Blanc, C. S. (1995) «From Immigrant to Transmigrant: Theorizing Transnational Migration», Anthropological Quarterly, 68.1, pp. 48-63.

Schmidt, G. D. (2013) Making Americans: Children's Literature from 1930 to 1960, Iowa City, University of Iowa Press.

Sota, M. de la (1949) Yanqui hirsutus. Pequeñas conversaciones sin importancia sobre los habitantes del nuevo mundo anglosajón, Buenos Aires, Editorial Sudamericana.

Sota, M. de la (1991) En torno al carácter vasco, Bilbao, Ekin.

«The Future of Basque Democracy» (1944) Basques: Bulletin of the Basque Delegation in the USA, 6, pp. 14-15. 
Totoricagüena, G. (2003) The Basques of New York: A Cosmopolitan Experience, Vitoria-Gasteiz, Gobierno Vasco.

Totoricaguena, G. (2005) Basque Diaspora: Migration and Transnational Identity, Reno, University of Nevada Press.

Vaczi, M. (2015) Soccer, Culture and Society in Spain: An Ethnography of Basque Fandom, London, Routledge.

Valle, T. del et al. (1985) Mujer vasca: imagen y realidad, Barcelona, Anthropos.

Zulaika, J. (1988) Basque Violence: Metaphor and Sacrament, Reno, University of Nevada Press. 
